\title{
Tsunami inundation characteristics along the Japan Sea coastline: effect of dunes, breakwaters, and rivers
}

Yusuke Yamanaka ${ }^{1,2^{*}}$ (1) and Takenori Shimozono ${ }^{2}$

\begin{abstract}
For Japanese coastal communities along the Japan Sea, where the risk of earthquake-induced tsunamis is deemed lower than that along the Pacific Ocean, tsunami disaster mitigation strategies have not been sufficiently developed. This study estimated the tsunami inundation characteristics for three major Japanese coastal cities along the Japan Sea. Based on tsunami simulations for representative coastal areas, we aimed to identify common vulnerabilities, which included those suggested by previous studies and local governments, to develop disaster mitigation strategies. Comprehensive simulations for tsunami propagation and inundation were performed for coastal areas in Akita City, Sakata City, and Niigata City based on earthquake and tsunami source scenarios developed by the Japanese Government for the Japan Sea area. To demonstrate the effectiveness of the estimated inundation characteristics, tsunami inundation was simulated for each coastal area under varying tsunami source conditions (including excessive tsunami magnitude) with a high resolution of the topography and infrastructure. Natural sand dunes, ports with man-made breakwaters, and rivers with levees are typical topographical features found in urbanized and densely populated areas along the Japan Sea coastline. According to the simulated results, the dunes and port breakwaters contribute significantly to decreasing the total amount of tsunami inundation for the areas behind them. However, the presence of the breakwaters also increases the tsunami heights in the areas immediately beyond the ports. Additionally, even the areas protected by the dunes might be exposed to an inundation risk in which the tsunamis invade a river channel, causing it to overflow. These findings were common to the coastal areas, and could be generally applicable to tsunami inundation for all coastal areas along the Japan Sea. Based on these results, the enhancement of existing infrastructure such as breakwaters and river levees should be the priority measure within tsunami risk-mitigation strategies; these, combined with natural resources such as dunes, can effectively mitigate tsunami disasters.
\end{abstract}

Keywords: Tsunami, Japan Sea, Akita City, Sakata City, Niigata City, Dune, Breakwater, River

\footnotetext{
*Correspondence: yyamanaka@sci.hokudai.ac.jp

1 Present Address: Institute of Seismology and Volcanology, Faculty of Science, Hokkaido University, N10W8, Kita-ku, Sapporo, Hokkaido 060-0810, Japan

Full list of author information is available at the end of the article
}

(c) The Author(s) 2022. Open Access This article is licensed under a Creative Commons Attribution 4.0 International License, which permits use, sharing, adaptation, distribution and reproduction in any medium or format, as long as you give appropriate credit to the original author(s) and the source, provide a link to the Creative Commons licence, and indicate if changes were made. The images or other third party material in this article are included in the article's Creative Commons licence, unless indicated otherwise in a credit line to the material. If material is not included in the article's Creative Commons licence and your intended use is not permitted by statutory regulation or exceeds the permitted use, you will need to obtain permission directly from the copyright holder. To view a copy of this licence, visit http://creativecommons.org/licenses/by/4.0/. 


\section{Graphical Abstract}

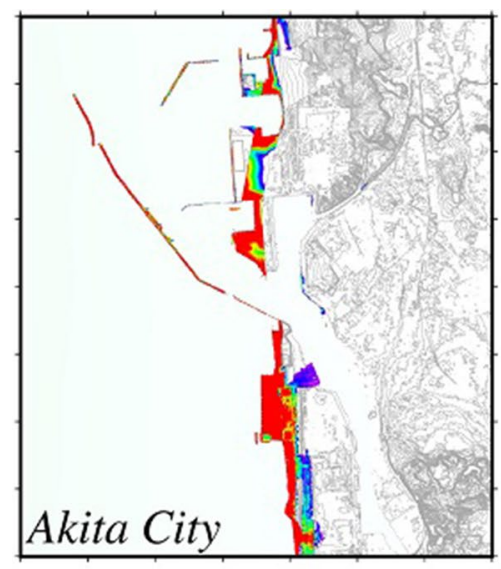

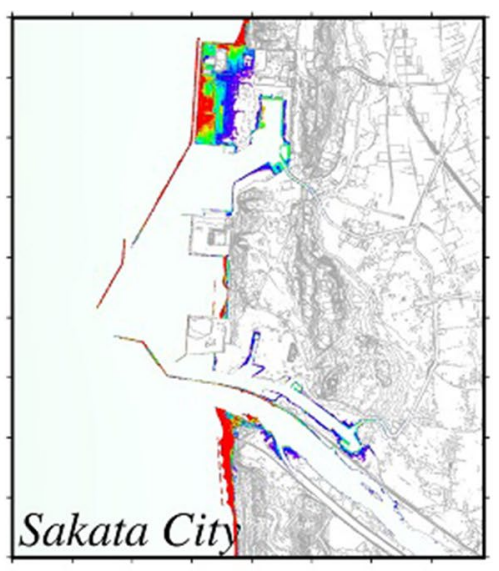

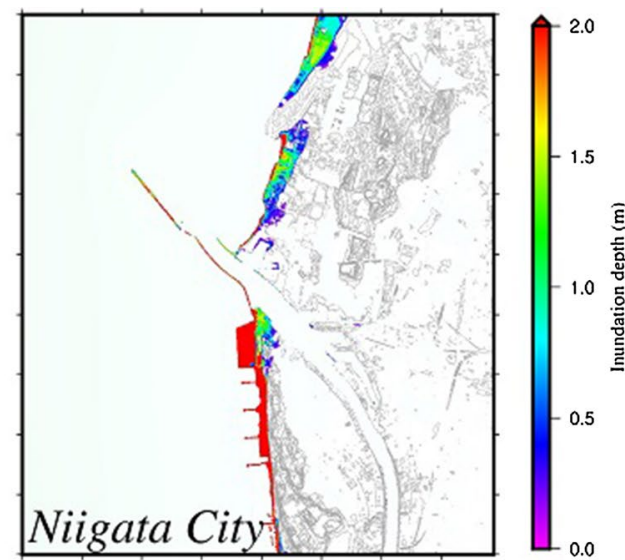

\section{Introduction}

Japanese coastal areas, including urbanized and densely populated areas, are prone to severe damage from tsunami inundation (e.g., Woessner and Farahani 2020). The coastal areas at risk from near-field tsunamis span the coastlines along the Pacific Ocean and the Japan Sea, covering metropolises and major ports. The regions bordering the Pacific Ocean have typically been struck by tsunamis generated by earthquakes in subduction zones, such as the Japan Trench (e.g., Satake et al. 2013) and Nankai Trough (e.g., Tanioka and Satake 2001). Earthquakes occurring in subduction zones have been considered to occur repeatedly dominated by several factors such as the geological structure and the convergence rate. Nankai Trough earthquakes are typical examples of repeatedly occurring earthquakes. Historical documents have indicated that large earthquakes repeatedly occurred with intervals of 100-200 years over a long term (Thatcher 1984). These earthquakes generated large tsunamis that struck the coastal areas. There are records and survey results of recent tsunami inundation and damage in the coastal areas (e.g., Hatori et al. 1983), and deposits for paleo tsunamis were also found (e.g., Fujino et al. 2018). The government has therefore promoted tsunami hazard mitigation measures along the Japanese coastlines of the Pacific Ocean, where earthquake-induced tsunamis reoccur at moderate intervals and for which a great wealth of such observation data exist. By contrast, subduction zones generating megathrust earthquakes comparable to those in the Pacific Ocean do not exist in the Japan Sea; however, many active faults exist over the area. The coastal areas of the Japan Sea have experienced large tsunamis produced by earthquakes of this type: for example, the 1983 Nihonkai-Chubu earthquake tsunami (e.g., Shuto 1985). However, as Kojima et al. (2017) indicated, planning for tsunami disaster mitigation along the Japan Sea coast has not been as developed as for the Pacific coast. This is because the probabilities of tsunami along the Japan Sea coast were considered to be significantly lower than those for the Pacific coast because of low seismic activity (or long recurrence intervals) in the Japan Sea area (Rikitake and Aida 1988). Because tsunamis are not generated frequently owing to the lower seismic activity, the record of tsunami inundation characteristics is not comprehensive enough to develop disaster mitigation strategies for communities along the Japan Sea. Considering the insufficient amount of observation data, numerically estimating tsunami inundation characteristics is one of the most realistic methods of contributing to the development of a robust disaster mitigation strategy along the coastal area. Therefore, this paper identifies, overviews, and summarizes the tsunami inundation characteristics of the Japan Sea area based on numerical simulations under probable source scenarios.

Tsunami sources that may significantly impact each region bordering the Japan Sea were uniquely assumed by the local governments for estimating future tsunami hazard. However, in 2014, the Japanese Government (namely, the Ministry of Land, Infrastructure, Transport and Tourism (MLIT)) listed 60 potential tsunami sources based on a comprehensive investigation. These sources, numbered from F01 to F60, were considered in this study (Fig. 1a). As they should be the most realistic source scenarios to represent future tsunami disasters along the Japan Sea, tsunami propagation and inundation characteristics based on these scenarios were estimated (e.g., Kojima et al. 2017; Mulia et al. 2020; Suzuki et al. 2018; Wu and Satake 2018; Sato et al. 2020; Yamanaka and Shimozono 2021; Yamanaka et al. 2019). The results of these previous studies can significantly 


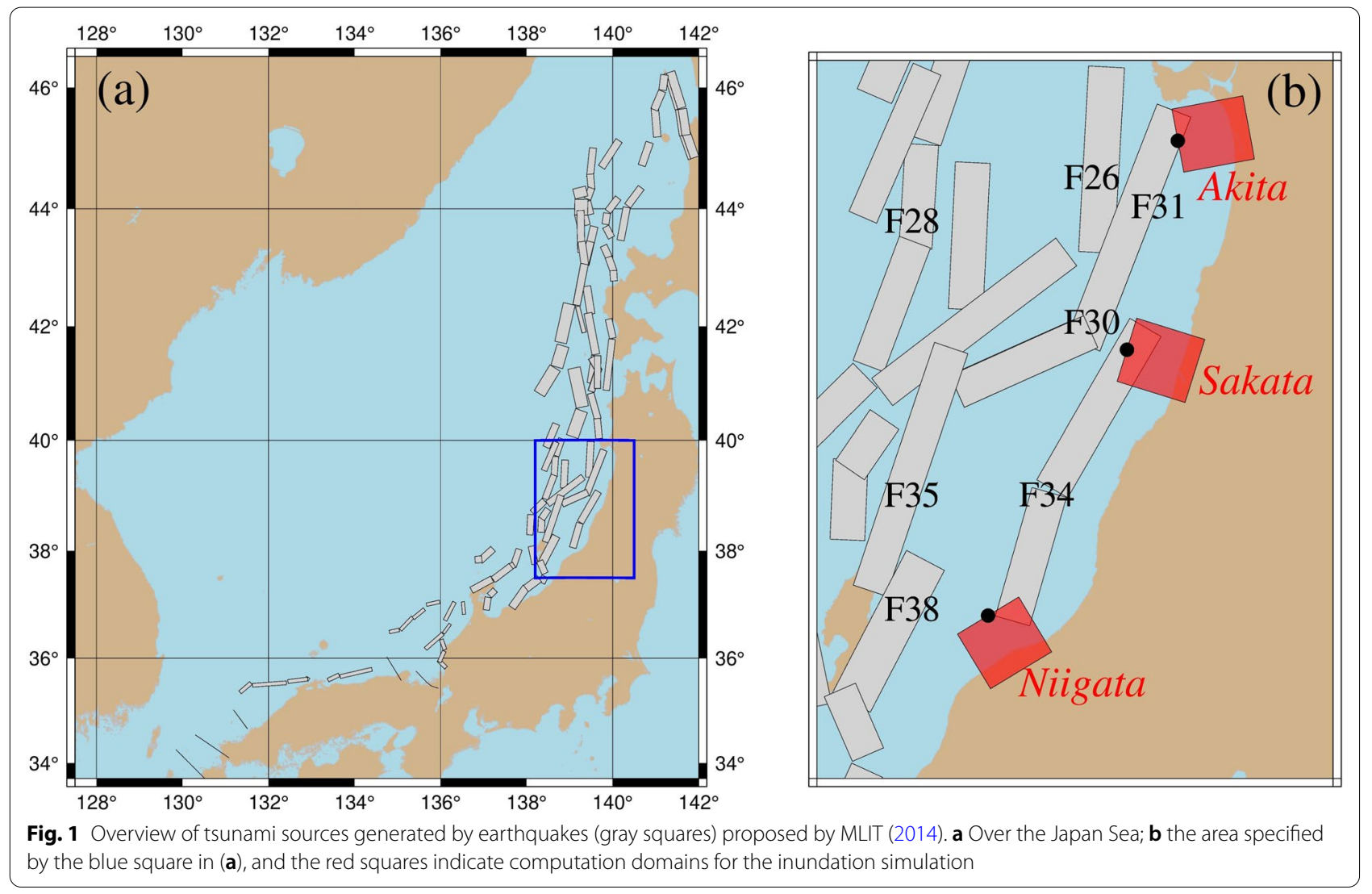

contribute to the development of disaster mitigation strategies; however, knowledge of the tsunami inundation characteristics is still limited to specific coastal areas. Local governments estimated the worst inundation using sources, including the MLITs (2014) ones (e.g., Akita Prefecture 2016; Niigata Prefecture 2017; Yamagata Prefecture 2016), and reported that dunes and rivers might be key to decreasing or increasing tsunami inundation in each coastal area (e.g., Niigata Prefecture 2017). Kojima et al. (2017) simulated a tsunami inundation with a spatial resolution of $10 \mathrm{~m}$ for Sakata City, one of the major port cities along the Japan Sea, using MLIT's (2014) sources. Although Kojima et al. (2017) investigated the inundation characteristics of only the coastal area of Sakata City in high-resolution geometry, they highlighted that a port breakwater and dune contributed significantly to reducing tsunami inundation in the city, and also suggested that these might be essential factors in characterizing tsunami inundation along the Japan Sea coastline. Sato et al. (2020) used the sources to estimate the tsunami inundation in order to quantify the expected hazard level at Niigata City, which is also a major port city within the area. Sato et al. (2020) had similar conclusions to those of Kojima et al. (2017). These findings were also reported as results in Project on Earthquakes and Tsunamis in the Japan Sea (2021), which were supported by the estimations of the local governments listed above. However, the results for the inundation characteristics estimated in most of these studies and reports were qualitative and remain to be quantified. Furthermore, the previous studies did not focus sufficiently on detailed tsunami inundation characteristics under the source scenarios. Therefore, it is necessary to thoroughly investigate and quantitatively estimate the characteristics of different coastal areas and compare them to identify common vulnerabilities for the Japan Sea coasts.

With this aim in mind, the primary objective of this study was to estimate tsunami inundation characteristics in three coastal areas facing the Japan Sea from MLIT's (2014) source scenarios. The areas targeted by this study were three major port cities that have urbanized and populated areas near the shoreline: Akita City, Sakata City, and Niigata City (Fig. 1b). Based on the simulations, this study investigated the common characteristics of tsunami inundation over the Japan Sea coasts and aimed to identify essential factors to inform the development of a reasonable disaster mitigation strategy for these areas. 


\section{Simulation of large-scale tsunami propagation}

This study firstly simulated a large-scale tsunami propagation. The initial tsunami deformations were modeled as vertical displacements at the 60 sources presented by MLIT (2014), based on the method of Okada (1985), and sea surface change due to the bathymetric effect were further considered for the deformations (Tanioka and Satake 1996). Note that rupture velocity, duration, and rise time were not considered when estimating the deformation. The computation domain was obtained from the General Bathymetric Chart of the Oceans with a 30 arc-sec resolution (Weatherall et al. 2015). A reflective boundary condition was assigned along the shores; the propagation of each deformation was then numerically solved for an elapsed time of $2 \mathrm{~h}$ after earthquake occurrence based on a linear long wave model in a spherical coordinate system, which can be obtained from Goto's (1991) model with a non-dispersive assumption.

Figure 2 summarizes the time series of the simulated change in water surface elevation from the mean sea level at representative grid points as $\eta(\lambda, \theta, t)$, as indicated by the black circles in Fig. 1b. Here, $\eta$ denotes the water surface elevation change (or, deformation) due to a tsunami, $\lambda$ denotes the latitude, $\theta$ denotes the longitude, and $t$ denotes time. These grid points have still-water depths of $\sim 90, \sim 140$, and $\sim 120 \mathrm{~m}$ off Akita, Sakata, and Niigata, respectively. Figure 2 also highlights up to three of the most influential (largest $\eta$ ) tsunamis for each location. As shown in Fig. 2, the influential tsunamis were maximized during their primary waves at all locations. This was because their source locations were located in the vicinity of the targeted coastal areas (Fig. 1b). Such large deformation produced near the coastal areas is expected to propagate toward and inundate the coastal areas, having a significant impact. Based on these results, tsunami inundation under the top three influential source scenarios for each area is investigated in the following section.

\section{Simulation of tsunami inundation}

The computation process for the inundation simulation presented in this section was similar to that of Yamanaka and Shimozono (2021).

First, a high-resolution computational geometry for the tsunami inundation simulation was constructed in a rectangular coordinate system of $(x, y)$ using two datasets: the M7000 digital bathymetric chart provided by the Japan Hydrographic Association and digital elevation models from the Geospatial Information Authority of Japan (Fig. 3). Spatial resolutions of 5 and $10 \mathrm{~m}$ were applied to the digital elevation models. However, the model with the resolution of $5 \mathrm{~m}$ did not cover coastal areas completely, since elevation data were lacking for certain areas; therefore, the computational geometries were constructed based on a combination of the two digital elevation models (Yamanaka and Shimozono 2021). The computational areas shown in the left panels in Fig. 3 were resolved into grid-space areas using the digital elevation model with a spatial resolution of $5 \mathrm{~m}$; the resultant blank areas were further filled by linearly interpolating $10 \mathrm{~m}$ resolution data. The Akita Port, Sakata Port, and Niigata-Nishi Port were located near the middle of the computation areas for Akita City, Sakata City, and Niigata City, respectively. Their breakwaters were several kilometers long, and were accurately resolved, as confirmed in Fig. 3. In addition to the port breakwaters, there are dunes developed along the shores and rivers flowing through to the sea in these areas (Fig. 3). These elements are typical in urbanized and densely populated areas along the Japan Sea. As dunes are less developed in areas with ports and river mouths, these areas might be vulnerable to tsunamis. As bathymetry data in ports and river channels were inaccurate in the datasets, constant values of 10 and $2 \mathrm{~m}$ were assigned to the port and river areas, respectively, as still-water depths. The stillwater depth was spatially smoothed in contiguous areas between a river and port and between a river and sea area.

The right panels in Fig. 3 show the magnified views of the areas enclosed by dashed squares in the left panels. Several cross-sectional slices, denoted L(P), were drawn over rivers and dunes to investigate the simulated results, and Additional file 1: Table S1 indicates the locations intersected by the lines. As Kojima et al. (2017) indicated for Sakata City, the breakwaters of the port are a key factor in reducing tsunami inundation, but could collapse during earthquakes and tsunamis. Determining the timing, extent, and rate of growth of the collapse is a challenge and, therefore, difficult to simulate accurately. Thus, in this study, the inundation simulation was performed using two computational geometries representing the best- and worst-case scenarios: with breakwaters and without (Kojima et al. 2017). By comparing the two simulated results, the effects of breakwaters on tsunami inundation were shown for each targeted area. Additionally, the breakwaters and river channels had a significantly smaller-scale geometry than that of dunes; the former two only occupied a few dozen domains (10 $\mathrm{m}$ by $10 \mathrm{~m}$ grid squares) in cross-sectional directions. Therefore, to investigate the effect of the meshing resolution on the simulation results, two computational geometries were produced: one with $10 \mathrm{~m}$ resolution and the other with $5 \mathrm{~m}$. For constructing $10 \mathrm{~m}$ resolution geometries from the $5 \mathrm{~m}$ resolution still-water depth (elevation) data, the depth at a grid point was calculated as the mean of the four corresponding depths from the $5 \mathrm{~m}$ resolution 

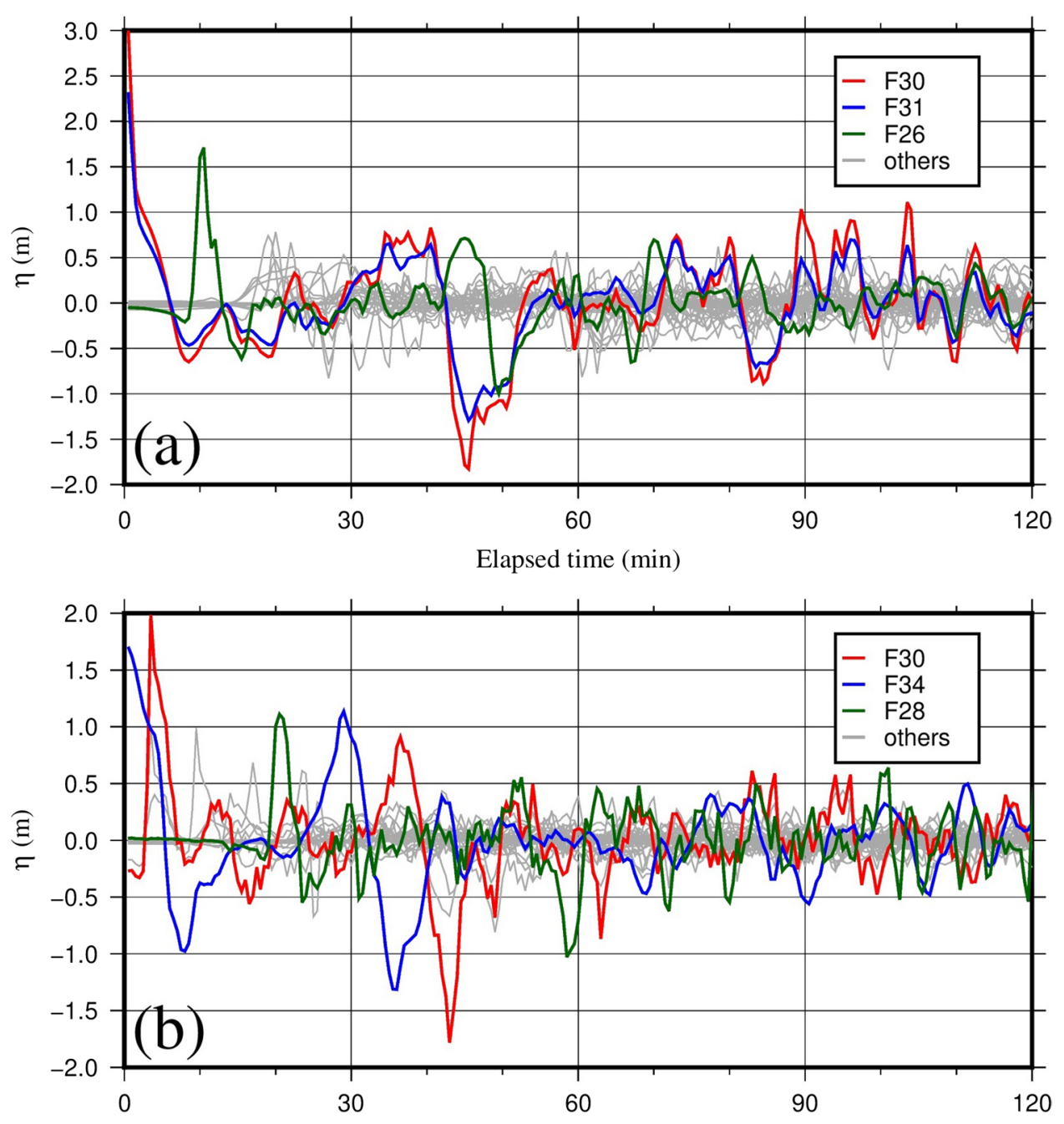

Elapsed time (min)

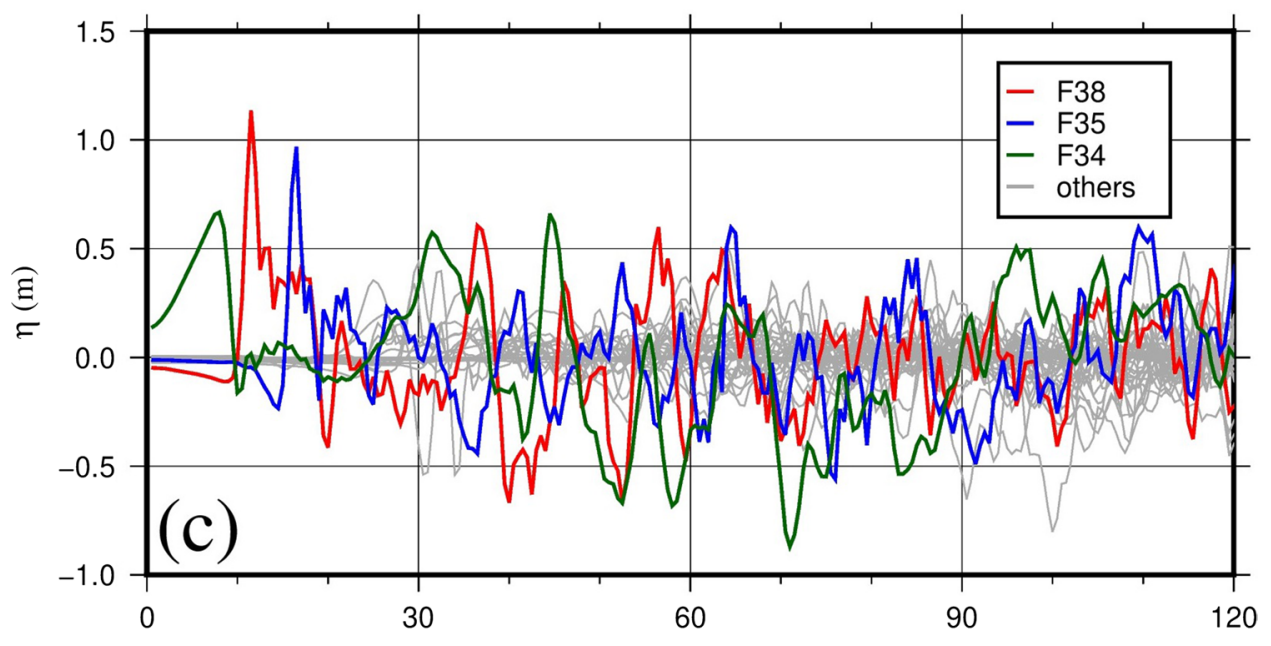

Elapsed time (min)

Fig. 2 Time series of water surface elevation change at locations specified by the black circles in Fig. 1b. a Off Akita; b off Sakata; c off Niigata 


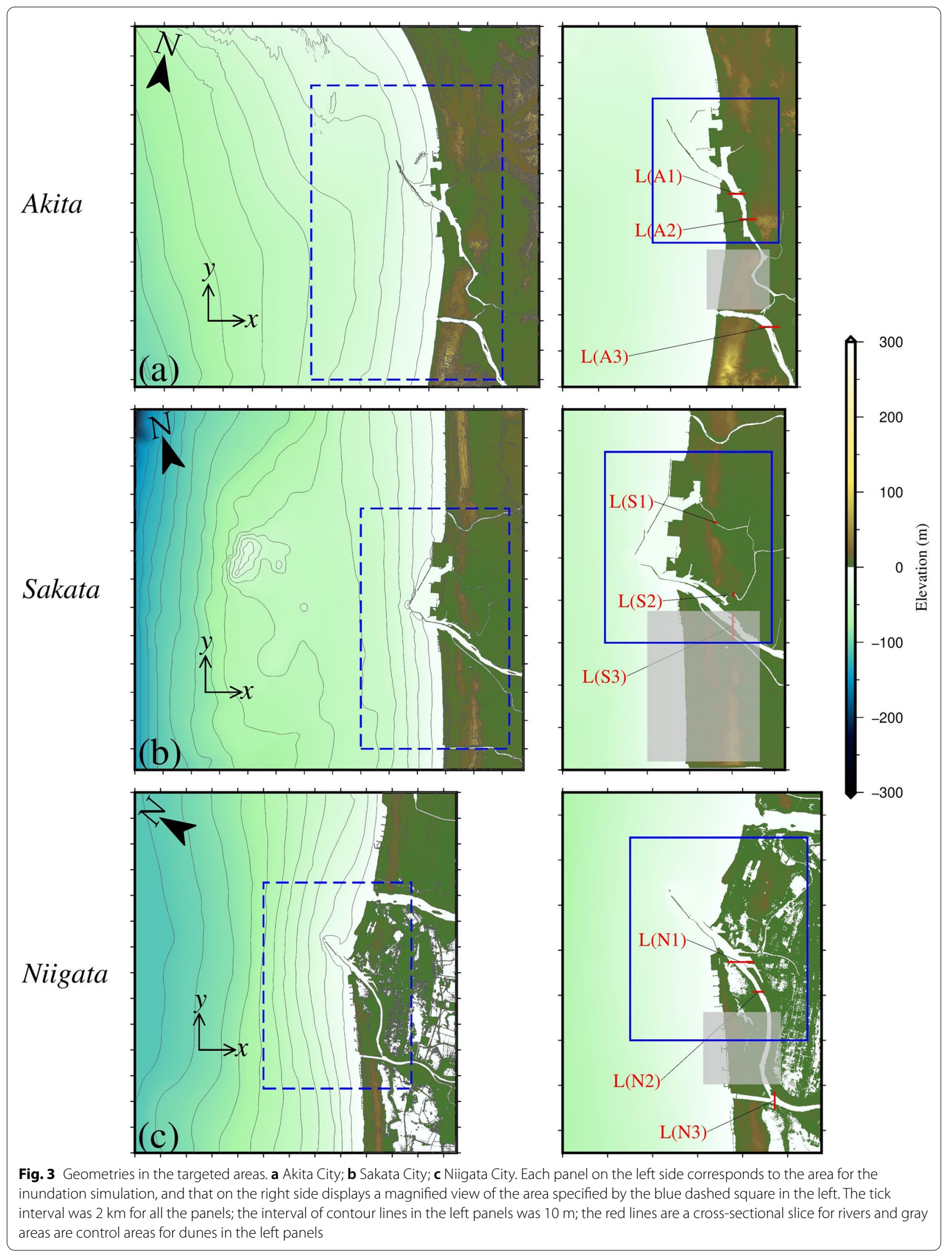


geometry. Over these geometries, tsunami inundation was simulated under the highlighted source scenarios for each targeted area. The computational conditions are summarized in Additional file 1: Table S2.

MLIT (2014) assumed a scaling relation for earthquake faults in the Japan Sea to develop the source models. To account for uncertainty in the scaling relation, they increased the expected slips by $1.5 \mathrm{~m}$, resulting in a source model with a one-sigma level slip $\left(D_{\sigma 1}\right)$. The value of $1.5 \mathrm{~m}$ corresponds to a standard deviation value for average slips in developed source models for each of the 1983 and 1993 earthquake events (MLIT 2014); the one-sigma level slip $\left(D_{\sigma 1}\right)$ presents a slip amount, including the originally expected slip and the additional one of $1.5 \mathrm{~m}$, on each source segment. However, in this study, tsunami inundation under scenarios with a three-sigma level slip $\left(D_{\sigma 3}\right)$, rather than considering concentrated large slips in source areas, was simulated to sufficiently cover the source uncertainty. The large-scale tsunami propagation was simulated based on the linear theory with a one-sigma level slip scenario; therefore, the simulated results under the three-sigma level slip scenario can be obtained by considering a factor of $D_{\sigma 3} / D_{\sigma 1}$ for the simulated results under the one-sigma level scenario. Therefore, the initial sea surface deformation $\eta(x, y, 0)$ in the computation area for the inundation simulation was determined using the simulated results with a factor of $D_{\sigma 3} / D_{\sigma 1}$. Note that tectonic changes due to co-seismic displacement were not considered for land subsidence. In addition to the initial deformation, the changes in the water surface elevation along the left edge of the computation domain were specified as an incident boundary condition $\left(\eta\left(x_{0}, y, t\right)\right)$ using the simulated results with a factor of $D_{\sigma 3} / D_{\sigma 1}$. The tsunami inundation was estimated based on a computation system, a one-way nested grid system, in which the numerical simulations in the coarser- and finer-resolution domains were performed independently. An open boundary condition was assigned to the other edges of the domain in the sea area.

The tsunami inundation simulation was based on a nonlinear long wave model (Goto et al. 1997). The values for Manning's roughness were determined to be 0.030 and $0.025 \mathrm{~m}^{-1 / 3} \mathrm{~s}$ for land and water areas, respectively; a moving boundary condition was assigned at a boundary between sea and land. The Japan Sea is a semi-closed sea area surrounded by the continent and islands, including Japan; astronomical tide level changes in the area are insignificant compared with the Pacific Ocean side (e.g., Odamaki 1989); hence, the tide level variations were not considered in this study. Additionally, no river discharge was assigned to the river channels. Therefore, water surface levels in the sea and river channels were determined to remain at $0 \mathrm{~m}$ until the earthquake occurred. Tsunami inundation due to the primary wave was estimated with time steps of 0.08 and $0.04 \mathrm{~s}$ for the computation geometries with resolutions of 10 and $5 \mathrm{~m}$, respectively.

Additional file 1: Figure S1 shows the cumulative inundation area in the computational area over time to determine when the expansion of inundation due to the primary wave ended. According to Additional file 1: Figure S1, the inundation likely almost ended within $45.0 \mathrm{~min}$ after the earthquake occurrences in each area. Accordingly, the tsunami inundation characteristics generated from the time of earthquake occurrence up to $45.0 \mathrm{~min}$ after were subsequently investigated. Additional file 1: Figure S1 also indicates a few discrepancies between the inundation areas simulated with the different resolutions.

\section{Inundation characteristics Dune-dominated areas}

Figures 4, 5, and 6 show the relationships between ground elevation and the maximum run-up height (i.e., how high the waves wash up onto the dunes) based on the results simulated with a resolution of $5 \mathrm{~m}$. In these figures, the variations in the top elevation and run-up heights along the shoreline are compared in the top-right panels, and it was confirmed that the run-up heights were significantly lower than the top elevations of each dune. The source scenarios used in the inundation simulation were the most critical scenarios for each targeted area among all the sources proposed by MLIT (2014) and were further increased to the three-sigma level from the one-sigma level. Even in such a scenario, the tsunamis did not overflow the dunes. Additionally, as shown in Figs. 4, 5, and 6 , the presence of port breakwaters did not have a significant effect on inundation over dunes; however, dune elevation did have a significant effect. These results demonstrated that tsunamis were unlikely to reach the top elevation of the dunes to greatly inundate areas behind them. Therefore, it can be concluded that, in the Japan Sea, dunes have been protecting coastal areas located behind them from tsunamis. The lower panels in Figs. 4, 5 , and 6 show cross-sectional slices of the dune and the maximum sea surface elevation, inundation height, and run-up height. As these panels show, the tsunamis did not exceed the top elevation of the dunes, whereas they overflowed several locally elevated areas between the dunes and the shores, as observed for the Akita and Niigata cities. Areas with the potential to be inundated do not correspond to the most urbanized areas in the cities, but are occasionally sub-urban residential areas. Therefore, it is concluded that residential areas behind the 

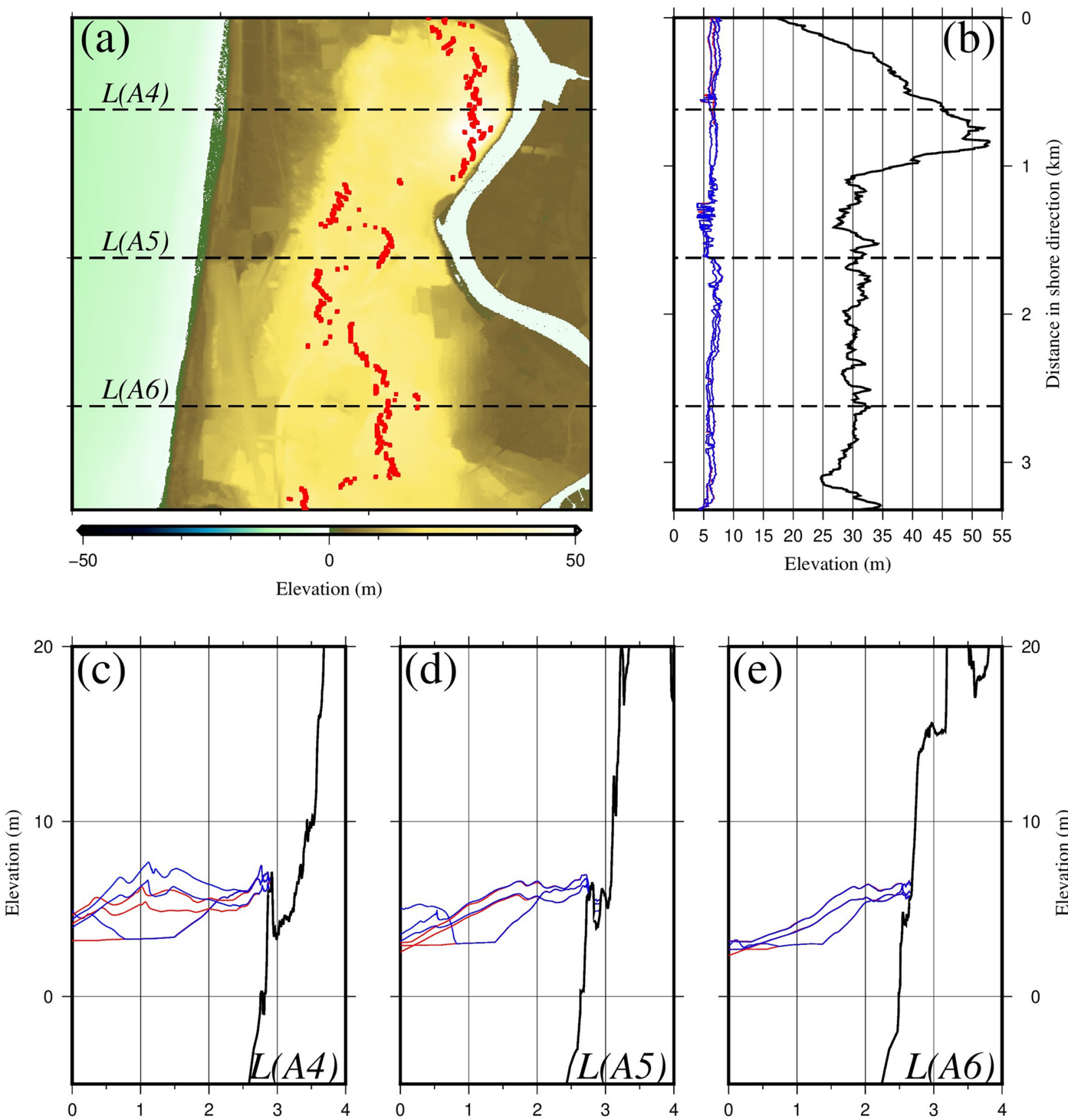

Distance in cross-shore direction $(\mathrm{km})$

Distance in cross-shore direction $(\mathrm{km})$

Distance in cross-shore direction $(\mathrm{km})$

Fig. 4 Tsunami characteristics over the Akita dune. a Geometry and cross-sectional slices within the gray area specified in the top-right panel of Fig. 3, red circles indicate the highest locations along the cross-shore direction, and the thick interval was $1 \mathrm{~km} ; \mathbf{b}$ alongshore variations in the maximum run-up heights and the top elevation over the dune; $\mathbf{c}-\mathbf{e}$ profiles of the dune and the maximum water surface elevation (inundation height) along the cross-sectional slices. Each line color in (b-e) indicates the dune profile (black) and the tsunamis in the F26, F30, and F31 source scenarios with the breakwaters (blue) and without (red)

dunes have low risk of being inundated, while those on the dune front have higher risk.

As shown in the top-left panels in Figs. 4, 5, and 6, the river channels are located behind the dunes. Near the mouths of the rivers, the heights of the dunes are relatively low, thus are more likely to be exceeded by tsunamis (e.g., Fig. 5a, b). Furthermore, since areas behind the dunes are occasionally on a river channel, they may 

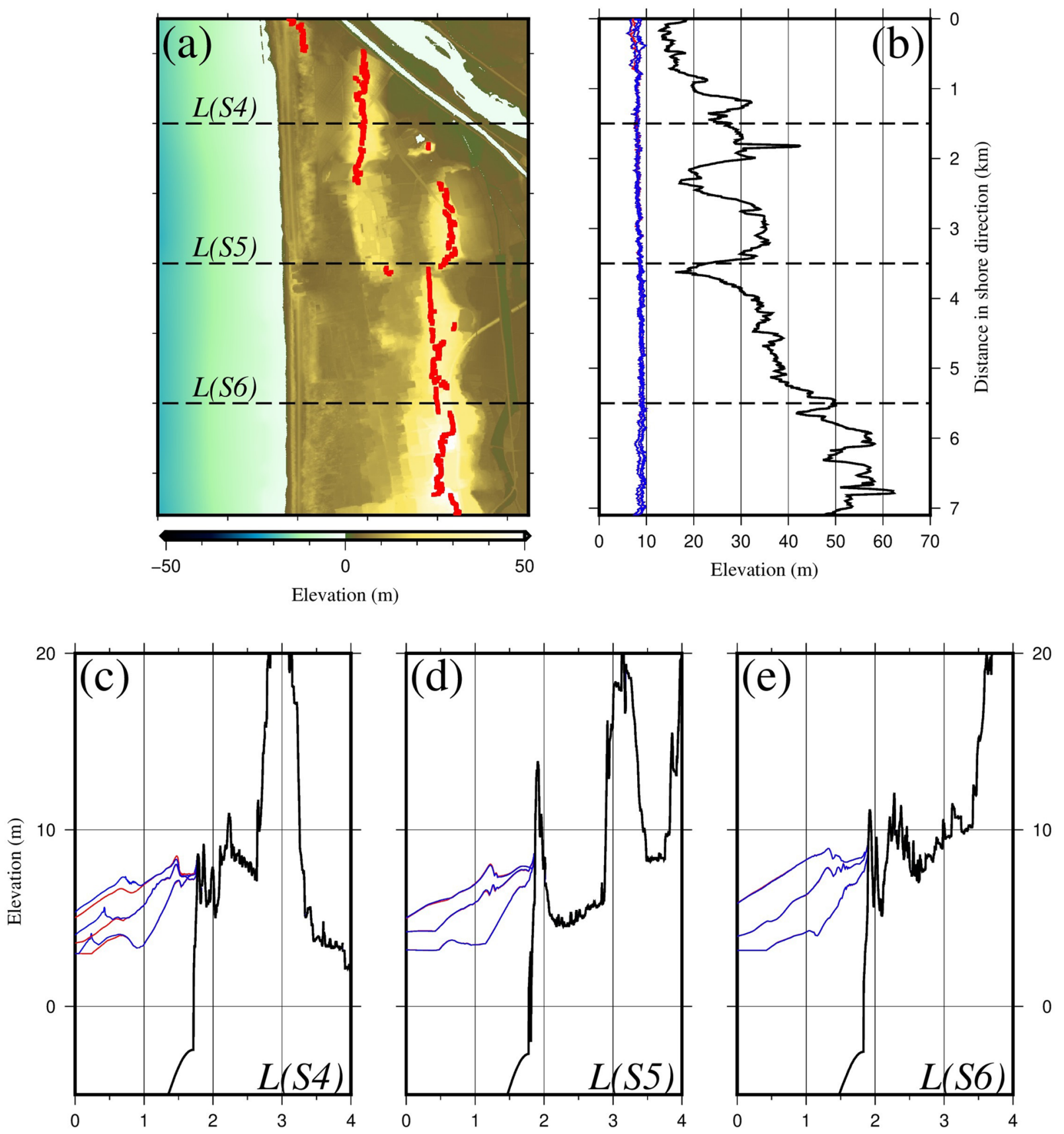

Distance in cross-shore direction $(\mathrm{km})$

Distance in cross-shore direction $(\mathrm{km})$

Distance in cross-shore direction $(\mathrm{km})$

Fig. 5 Tsunami characteristics over the Shonai dune. a Geometry and cross-sectional slices within the gray area specified in the middle-right panel of Fig. 3, red circles indicate the highest locations along the cross-shore direction, and the thick interval was $1 \mathrm{~km} ; \mathbf{b}$ alongshore variations in the maximum run-up heights and the top elevation over the dune; $\mathbf{c}-\mathbf{e}$ profiles of the dune and the maximum water surface elevation (inundation height) along the cross-sectional slices. Each line color in (b-e) indicates the dune profile (black) and the tsunamis in the F28, F30, and F34 source scenarios with the breakwaters (blue) and without (red)

be at risk of being inundated by a tsunami propagating through the channel. Comparing the elevations of each dune shown in Figs. 4, 5, and 6, it may be observed that the Niigata dune is lower than the others; one of the tsunami run-up heights is moderately comparable to the top elevation of that dune (Fig. 6e). This result suggests that of the three cities, Niigata City has the highest risk of a tsunami overflowing above the top elevation of a dune. 


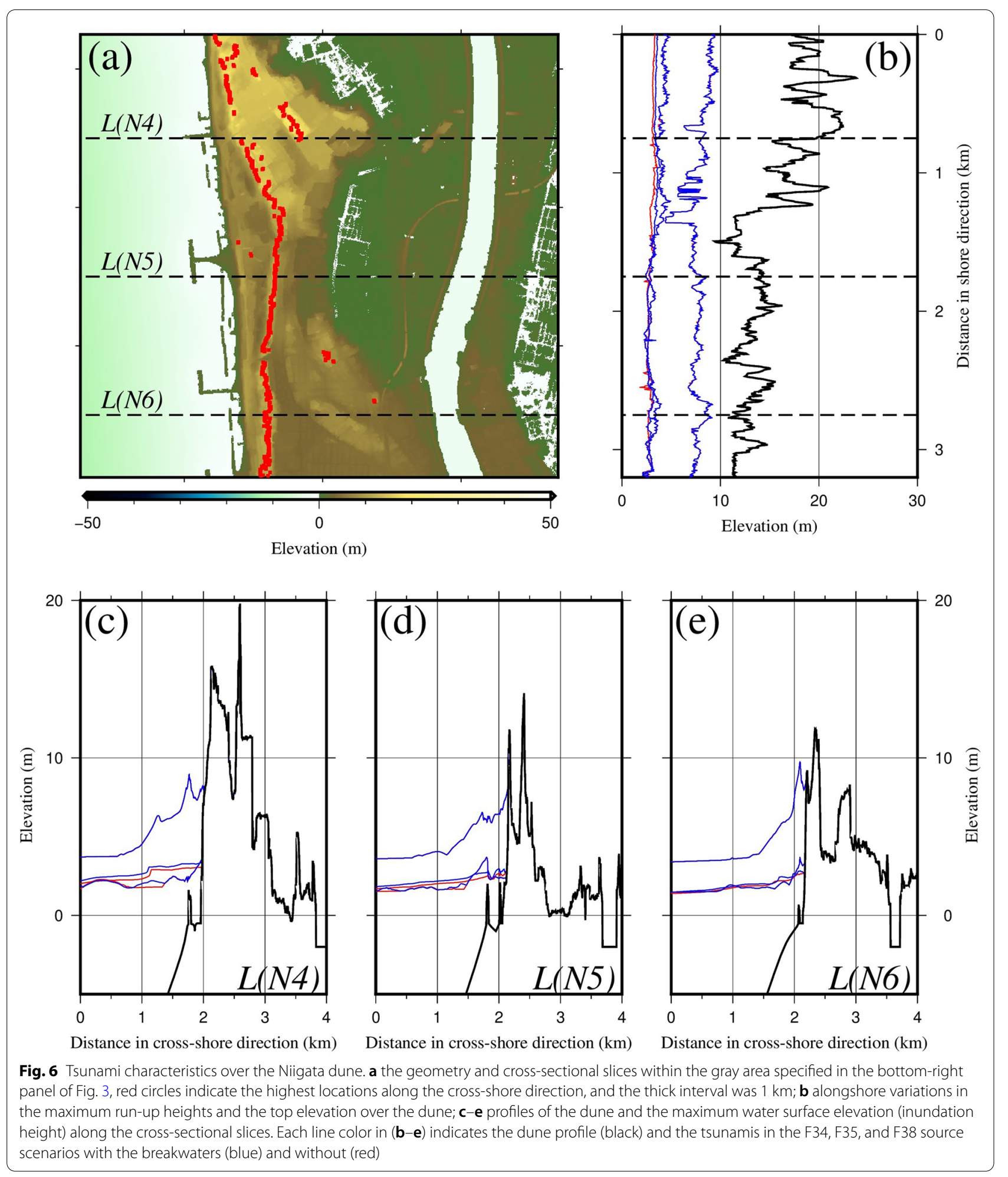

\section{Port areas}

Figure 7 shows snapshots of nearshore tsunami propagation over time at each targeted area based on the simulated results with a resolution of $5 \mathrm{~m}$. As shown in the figure, the incident tsunamis strongly reflected at the breakwaters and propagated along them in all the targeted areas. The reflected wave constructively superimposed onto the incident wave, resulting in a locally 

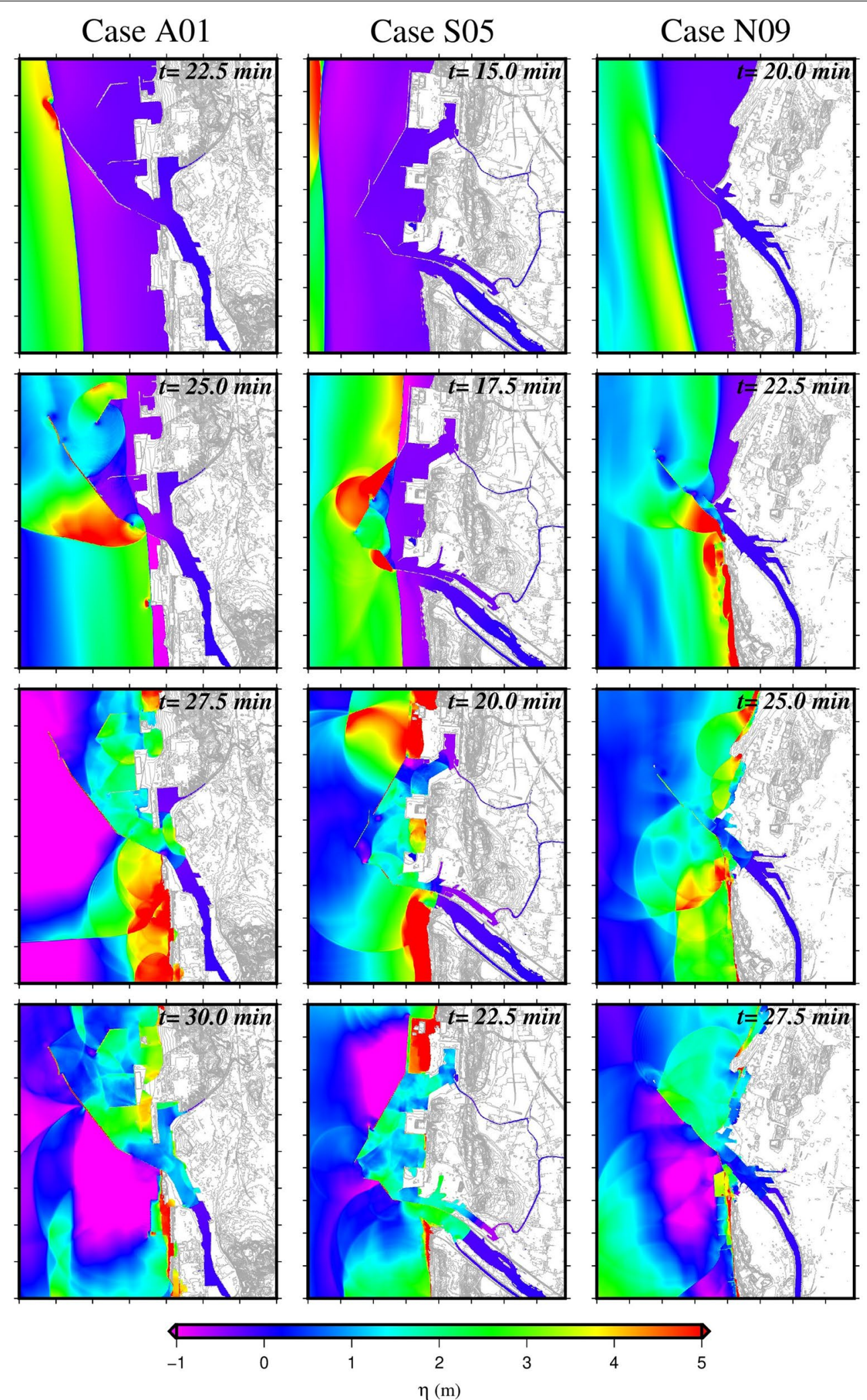

Fig. 7 Snapshots of representative nearshore tsunami propagations. The left, middle, and right panels correspond to the time series for Akita City, Sakata City, and Niigata City, respectively. The displayed areas correspond to the areas specified by the blue squares in the top-right, middle-right, and bottom-right panels in Fig. 3; the thick interval was $1 \mathrm{~km}$ 
concentrated wave outside the ports, as observed at $25.0 \mathrm{~min}$ for Scenario A01 (Fig. 7). The sea surface fluctuations in the ports protected by the breakwaters were likely to be moderate compared with the fluctuations outside. Additionally, as observed at $27.5 \mathrm{~min}$ for Scenario N09, a relatively high sea surface level remained in the port due to the breakwater, although it was significantly decreasing outside. Figures 8,9 , and 10 show the maximum inundation depth generated up to $45.0 \mathrm{~min}$ for each targeted area. As expected from the results presented in Fig. 7, the inundation depth decreased significantly in areas behind the ports in which the breakwaters were used in the computation, compared with the scenarios in which they did not exist. This characteristic was identical regardless of the targeted area and source scenario (Figs. 8, 9, and 10). Figures 8, 9, and 10 also indicate that variations in the inundation depths depend significantly on source scenarios. However, the difference in the inundation pattern due to the resolution was not significant, not even for Niigata City, whose discrepancy is shown in Additional file 1: Figure S1. Accordingly, the results of the $5 \mathrm{~m}$ resolution simulations are presented hereafter.

A peak hold value for the maximum sea surface level or inundation height generated up to $45.0 \mathrm{~min}$ was extracted at each grid point, and the difference in the scenarios with the breakwaters and without $\left(\Delta \eta_{\max }\right)$ was calculated to quantitatively investigate the impact of breakwaters (Fig. 11). In Fig. 11, the degree of the impact of the breakwaters is shown using color intensity; blue indicates that the maximum water surface level would be reduced by the breakwater (i.e., positive impact), while red means that it would increase (i.e., negative impact). According to the figure, the breakwaters significantly reduced the maximum water surface level and inundation heights in and near the ports. To further demonstrate the impacts,

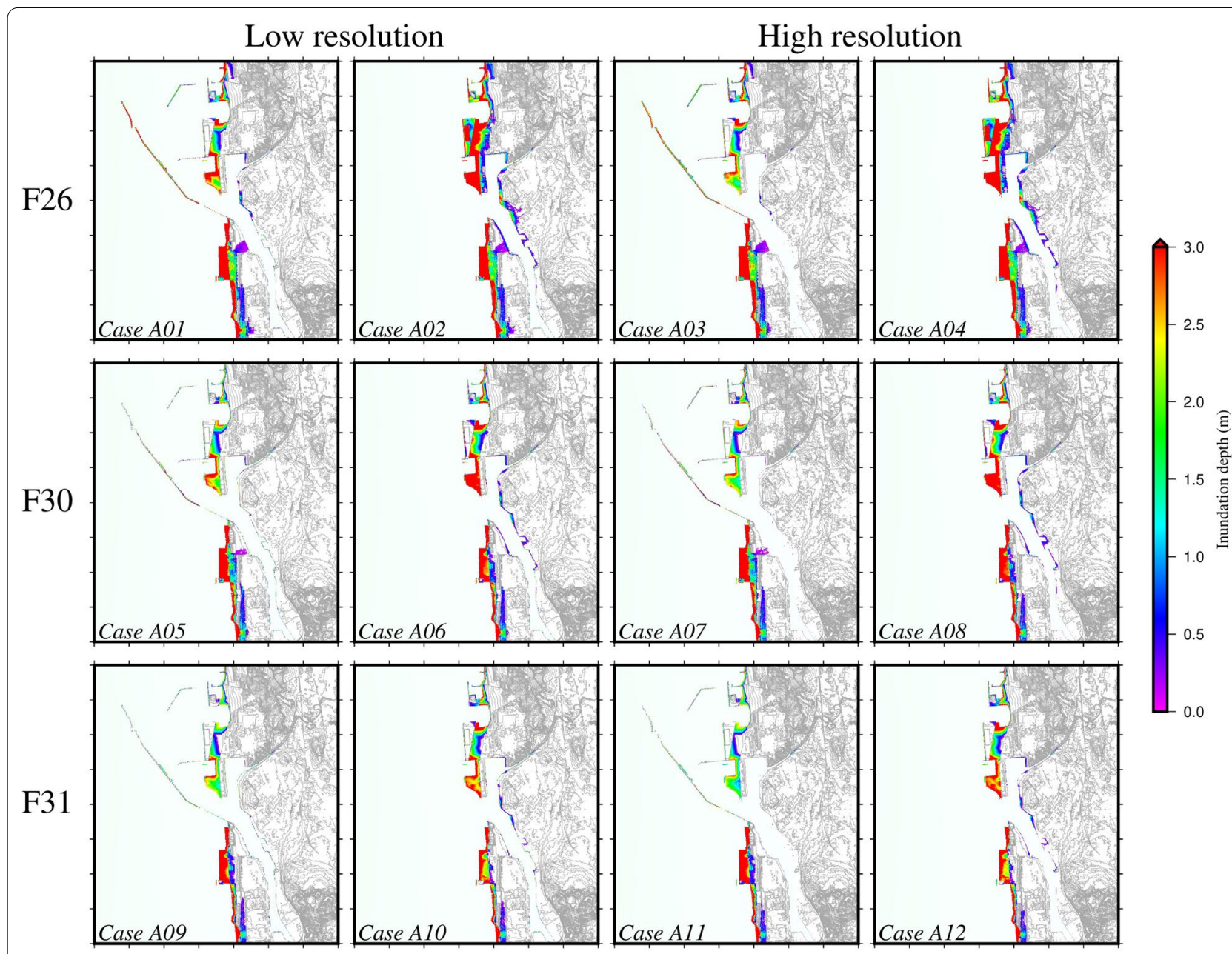

Fig. 8 Distribution of the maximum inundation depth at Akita City generated up to 45.0 min after the earthquakes. The displayed areas correspond to the areas specified by the blue squares in the top-right panel in Fig. 3; the thick interval was $1 \mathrm{~km}$ 


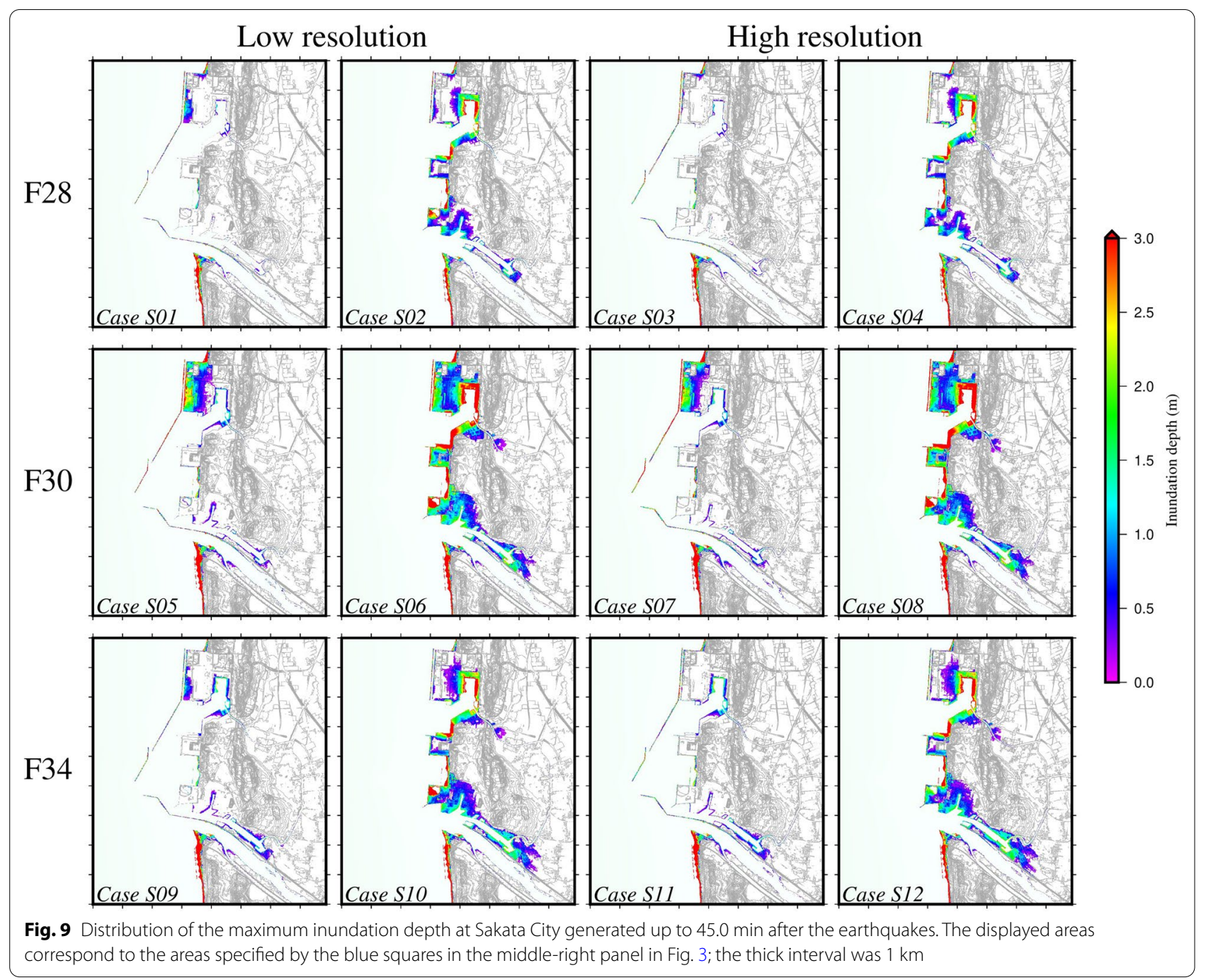

we counted the expected total population living in the inundation area (damaged population) for each computation result based on a dataset with a spatial resolution of $50 \mathrm{~m}$, which Microbase Co. (2010) built from the results of the national 2010 census. The results are summarized in Fig. 12 and include the population living in areas outside the targeted cities, but still covered by the computational area. According to this result, the damaged population decreased moderately in Akita City owing to the presence of breakwaters and decreased significantly in the other areas. This was because the presence of the breakwaters also decreased the total inundation area (Figs. 8, 9, and 10). These results demonstrate that breakwaters are key to reducing tsunami hazards in the Japan Sea, as Kojima et al. (2017) also indicated. By contrast, the port breakwaters increased the maximum sea surface level in areas immediately beyond the breakwaters, such as outside the ports and in the river channel of the Mogami River in Sakata City (Fig. 11). The increase resulted from a superposition of reflected and incident waves, i.e., the generation of a significant standing wave along the breakwater. This is an inevitable consequence of using breakwaters. Although the degree of the increase varied depending on coastal areas and tsunamis (Fig. 11), such an increase could be another characteristic common to port cities along the Japan Sea coastline. As discussed earlier, the breakwaters did not have a significant effect on tsunami inundation in the dune-dominated areas (Figs. 4, 5, and 6), whereas they were occasionally more influential in the other characteristic areas, e.g., river channels, as presented in the following section.

\section{River channels}

As outlined earlier, dunes developed along the shore direction interrupt the tsunamis, protecting inland areas behind them. However, tsunamis can still reach these 


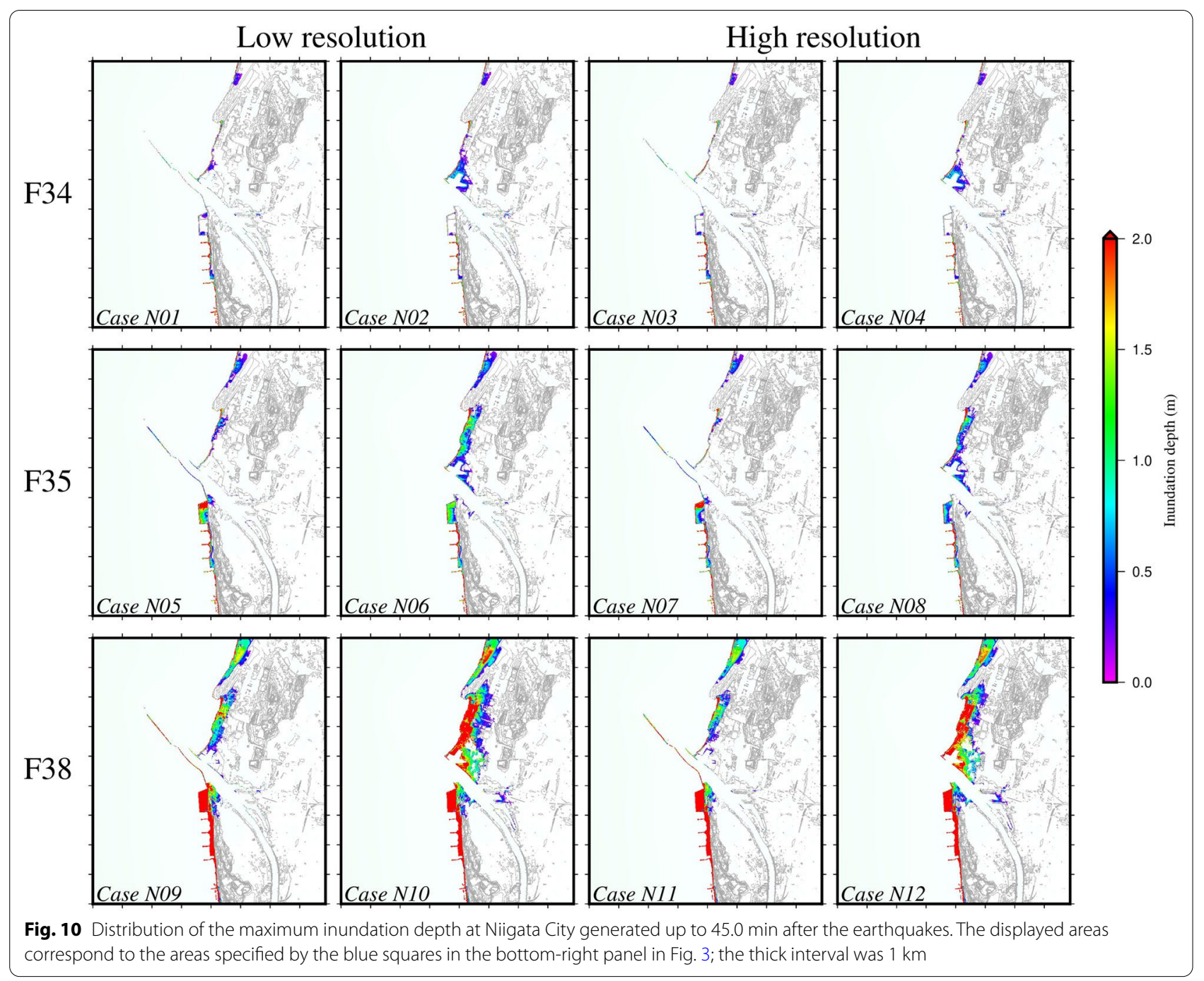

areas by invading the river channels located alongside them. Generally, in Japan, river levees have been developed at large-scale rivers to control river flooding associated with precipitation. It is crucial to determine whether tsunamis exceed existing river levees.

Figure 13 shows the maximum water surface levels over the cross-section of rivers specified in Fig. 3. The water surface levels go up to $\sim 3 \mathrm{~m}$ at $\mathrm{L}(\mathrm{A} 3)$ in the Omono River in Akita City and are significantly lower than the river levee. The Omono River is a large-scale river classified as an especially important river, Class A, which the Japanese Government directly manages. Large levees have been constructed along Class A rivers as a measure to control and manage river flooding. The water surface level in the rivers during a tsunami was significantly lower than the river levee, as observed at L(S3) for the Mogami River in Sakata City and L(N3) for the Shinano River in Niigata City; those rivers are also classified as Class A. As the Mogami River is located alongside Sakata Port, the influence of the breakwaters in the river channel appears as a negative impact, but still is insignificant compared with the levee heights. However, the levees are occasionally insufficient in height even for Class A rivers near the coast, as observed at L(N1) (Figs. 3 and 13). As observed at L(A1) and L(A2), no significant levee exists along the Akita Channel, an ex-river channel for the Omono River. In contrast, tsunami inundation would rarely cause Class A rivers to overflow in upstream regions. As populated areas are often located close to river mouths, measures may be necessary to reduce tsunami hazard risks.

Some river mouths are located in a port, as observed at the Akita Channel, Shinano River, Yutaka River, and Niida River (Figs. 3 and 13); therefore, they are surrounded and protected by breakwaters. As shown in 


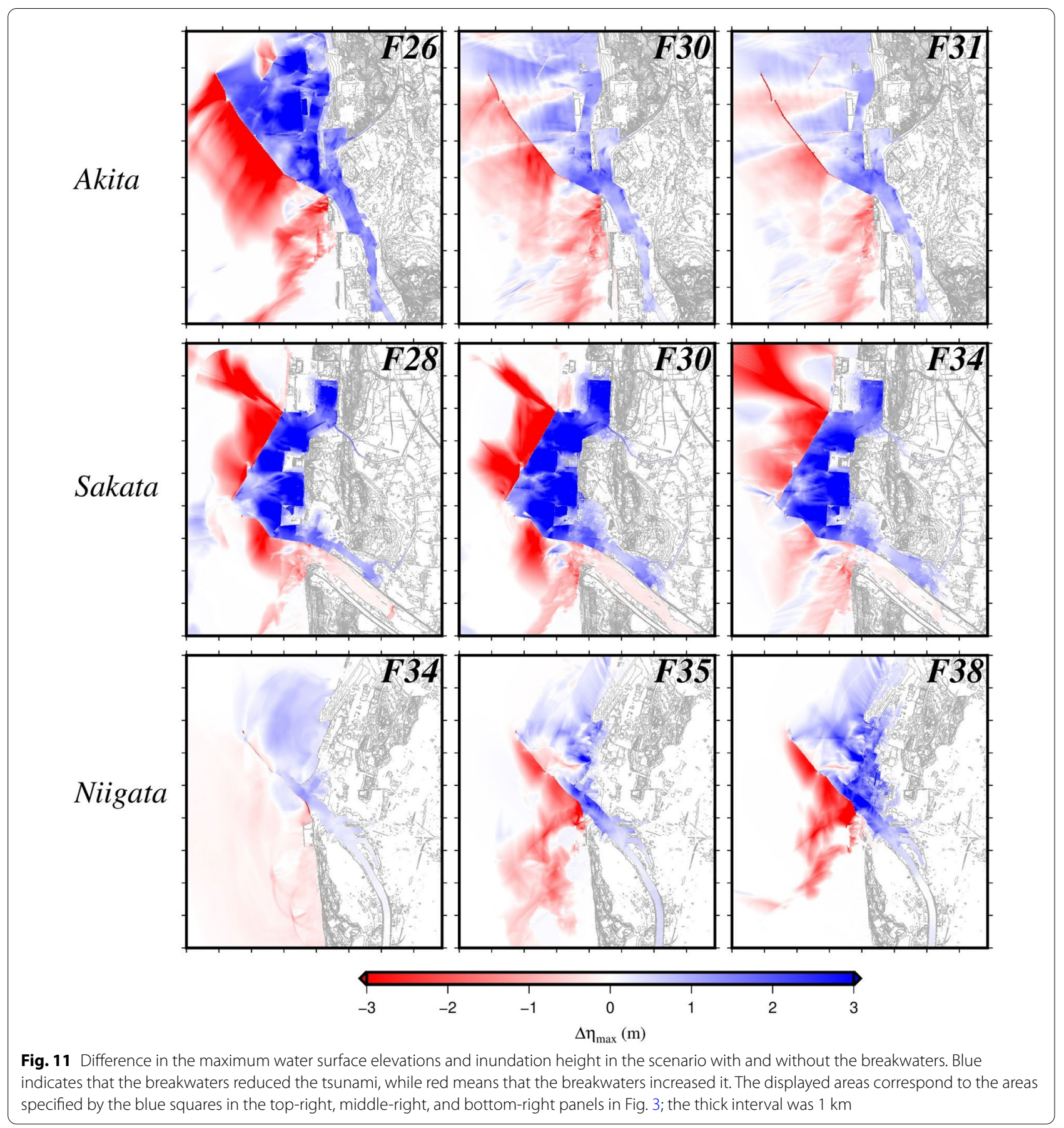

Fig. 13, in such a scenario, the breakwaters have a significant function in decreasing the water surface level in the river channel and reducing the total amount of flooding. Therefore, it should be ensured that existing breakwaters are sufficiently strong to withstand earthquakes and tsunamis. The smaller Yutaka and Niida Rivers in Sakata City are classified as an important river, Class B (as opposed to Class A), which a local government manages. As shown in Fig. 13, no significant levee exists along the two river channels; the importance of the breakwaters is more significant for them. Levees along Class B rivers tend to be insufficient, leading to higher inundation risk compared with Class A rivers, as shown in Fig. 13. Figure 9 also shows that the inundation expanded into the two rivers, causing them to overflow in several scenarios, while 


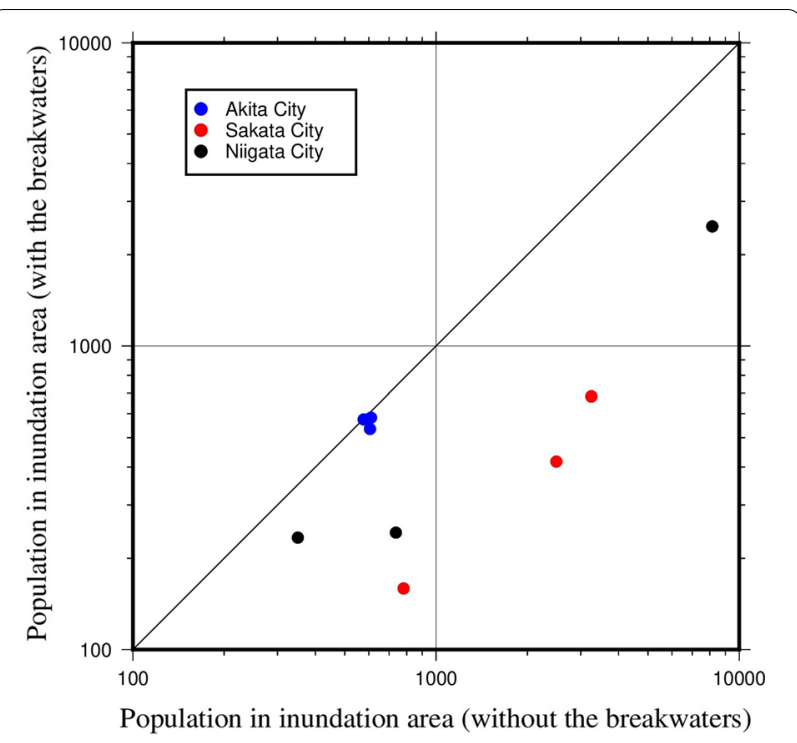

Fig. 12 Comparison of the total population within the inundation area in the scenarios with and without the breakwaters

a slight expansion was observed along the Mogami River; similar findings were reported by Yamanaka and Shimozono (2021).

Additionally, incorporating accurate bathymetry and river morphology changes occurring during a tsunami should be an essential task for fully understanding nearshore tsunami dynamics. According to Tanaka et al. (2014), a geometry developed in a river mouth area, such as sand spits, reduces the energy of the tsunami invading the river; this should be effective unless the tsunami magnitude is significant. Thus, it will be necessary to consider these aspects in future studies. Furthermore, sluices and levee underpasses are occasionally present along river channels. This study did not consider these elements, which may be several meters in width. Tsunamis invading underpasses may result in a scenario in which an open channel flow does not exist locally; tsunami inundation cannot be simulated seamlessly for such an area. Thus, the potential for tsunami inundation to expand into protected areas through sluices on river channels might still exist (Project on Earthquakes and Tsunamis in the Japan Sea 2021).

\section{Summary and conclusions}

In this study, expected tsunami inundation characteristics were estimated for the three major coastal areas (i.e., Akita City, Sakata City, and Niigata City) facing the Japan Sea based on the representative hazard source scenarios proposed by MLIT (2014). To account for uncertainties in the sources and the collapse of infrastructure, a slip amount having a three-sigma level was assumed in source scenarios, and simulations were performed with and without port breakwaters on the targeted areas. The results of this study cover the results of Kojima et al. (2017), Sato et al. (2020), and Yamanaka and Shimozono (2021) and inform the development of a reasonable disaster mitigation strategy for areas along the Japan Sea coastline.

By comparing the simulated results for the three major port cities, remarkable identical characteristics in tsunami inundation were highlighted. The most important finding to inform the disaster mitigation strategy was that dunes have been significantly protecting areas where no coastal dikes are available (e.g., Niigata Prefecture 2017). Dunes along the Japan Sea coastline have been developed by significant winds in the winter season, which are one of the characteristics of the Japan Sea. The coastal areas targeted by this study border the eastern margin of the Japan Sea where significant tsunami sources exist (MLIT 2014). The simulated run-up heights on the dunes were up to $\sim 10 \mathrm{~m}$, even in areas prone to significant tsunamis (Figs. 4, 5, and 6). Thus, in the Japan Sea, dunes higher than $\sim 10 \mathrm{~m}$ are expected to significantly protect areas behind them from tsunamis. We have not found evidence that the historical tsunamis in the Japan Sea greatly exceeded dunes (Kawakami et al. 2017); however, locally concentrated tsunamis may exceed a dune, as observed in the 1983 tsunami (Hatori 1995).

On account of the dunes, no significant tsunami inundation was simulated in the coastal areas. However, local inundation encroached around port and river mouth areas where dunes were insufficiently developed; such areas are more vulnerable to tsunamis. In these areas, infrastructure (i.e., breakwaters and river levees) that were not developed for tsunami prevention contribute significantly to protecting areas behind and alongside them from tsunamis, as long as they do not collapse. This is another characteristic of the Japan Sea coastline. Therefore, it may be necessary to further reinforce infrastructure to withstand earthquakes and tsunamis. Despite the presence of dunes, areas along a river may be inundated by tsunamis invading a river channel, if the river levee is not sufficiently high. Such risk is considered to be higher along Class B rivers than Class A rivers because the levees along the former tend to be insufficient compared with the latter. Thus, local areas-in which levees are insufficient in height and smaller-scale geometries such as sluices influence tsunami inundation-should be identified, and measures might be required to reduce the inundation risk.

The three areas are among the most populated along the Japan Sea. There are other smaller-scale coastal 


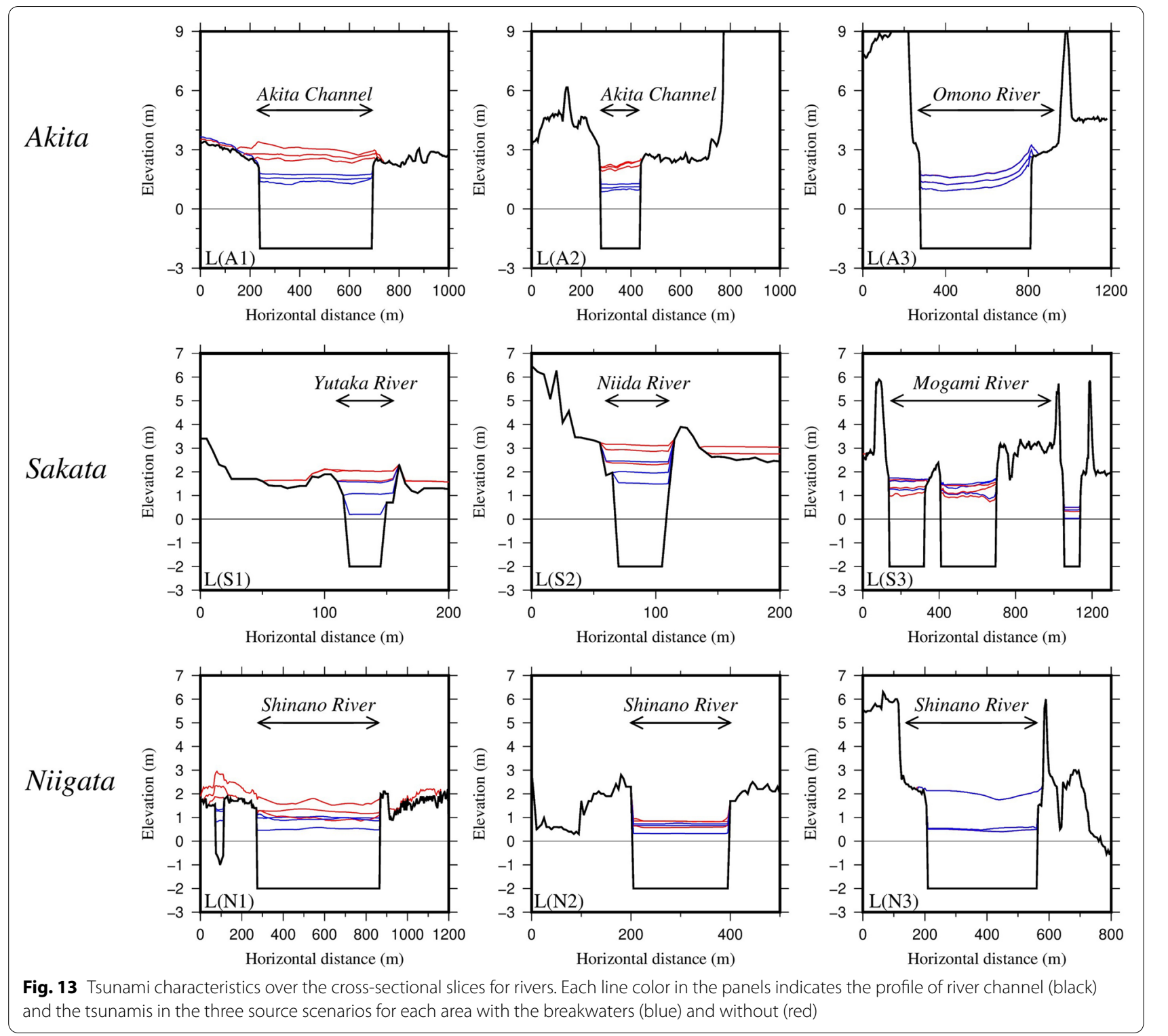

areas in the Japan Sea; these findings (i.e., the effects of dunes, breakwaters, and rivers) may be applicable as a general trend regardless of the population scale. However, the importance of infrastructure is expected to be lower for sparsely populated and highly elevated areas. In addition to the general characteristics listed above, tsunami inundation should also be characterized by other individual factors for each coastal area. As confirmed in Fig. 11, the breakwaters contribute to both a significant increase and decrease in the maximum water surface level outside the ports. Where the changes appear, and their magnitude, should strongly rely on the relationships between height, period, and angle of an incident tsunami, as well as geometric characteristics in the breakwaters. Consequently, the change and its magnitude should differ depending on the coastal area to influence the inundation pattern. Another possible factor to characterize the inundation locally could be the seasonal variation in river discharge, which this study did not consider. Generally, there is heavy snowfall in the winter season of Japan, affecting the Japan Sea side, increasing discharge and water surface levels in river channels in the snowmelt season. Therefore, the risk of tsunami inundation through rivers may vary over the seasons in which the tsunami occurs. The variation in the water surface level associated with the river discharge is a local factor in each basin and depends on weather conditions; the 
impact, alongside the effects of the river morphology change, should be assessed to mitigate the local tsunami inundation (e.g., Sato et al. 2020).

According to our simulated results, locally concentrated inundation around ports and near river mouth areas, as opposed to an inundation covering large areas, can be expected over the Japan Sea coasts. These findings suggest that local intensive measures should be suitable to protect urbanized areas from tsunamis in the Japan Sea. One such method can be to develop water gates to prevent tsunami invasion into river channels with insufficient levees. However, additional structures must be compatible with the existing infrastructure. Consequently, the enhancement of existing structures, such as breakwaters and river levees, should be the priority measure within the strategies. A quantitative evaluation of decreasing tsunami inundation by developing such measures will be necessary in future research (Project on Earthquakes and Tsunamis in the Japan Sea 2021).

\section{Abbreviation}

MLIT: Ministry of Land, Infrastructure, Transport and Tourism.

\section{Supplementary Information}

The online version contains supplementary material available at https://doi. org/10.1186/s40623-022-01579-5.

Additional file 1: Figure S1. Cumulative inundation area in the computation domain without the port breakwaters. Table S1. Summary of crosssectional slices. Table S2. Summary of computational conditions.

\section{Acknowledgements}

We thank the editor, Prof. Kenji Satake, and two anonymous reviewers for their constructive comments. All figures presented in this paper were printed using the Generic Mapping Tools (GMT) software of Wessel et al. (2013).

\section{Authors' contributions}

YY and TS conducted the numerical simulation and analyzed the simulation results; both authors contributed to the interpretation of the results. YY wrote the original draft of the manuscript. Both authors read and approved the final manuscript.

\section{Funding}

This study was supported by JSPS KAKENHI Grant Number $18 \mathrm{H} 01541$ and the Project on Earthquakes and Tsunamis in the Japan Sea from the Ministry of Education, Culture, Sports, Science, and Technology of Japan.

\section{Availability of data and materials}

The presented data are available from the corresponding author on request.

\section{Declarations}

Ethics approval and consent to participate

Not applicable.

\section{Consent for publication}

Not applicable.

\section{Competing interests}

The authors declare that they have no competing interests.

\section{Author details}

${ }^{1}$ Present Address: Institute of Seismology and Volcanology, Faculty of Science, Hokkaido University, N10W8, Kita-ku, Sapporo, Hokkaido 060-0810, Japan. ${ }^{2}$ Department of Civil Engineering, The University of Tokyo, 7-3-1 Hongo, Bunkyo-ku, Tokyo 113-8656, Japan.

Received: 29 September 2021 Accepted: 12 January 2022

Published online: 25 January 2022

\section{References}

Akita Prefecture (2016) https://www.bousai-akita.jp/pages/?article_id=293. Accessed on 22 Nov 2021 (written in Japanese)

Fujino S, Kimura H, Komatsubara J, Matsumoto D, Namegaya Y, Sawai Y, Shishikura M (2018) Stratigraphic evidence of historical and prehistoric tsunamis on the Pacific coast of central Japan: implications for the variable recurrence of tsunamis in the Nankai Trough. Quat Sci Rev 201:147-161. https://doi.org/10.1016/j.quascirev.2018.09.026

Goto C (1991) Numerical simulation of the trans-oceanic propagation of tsunami. Rep Port Harb Res Inst 30:4-19 (In Japanese)

Goto C, Ogawa Y, Shuto N, Imamura F (1997) Numerical method of tsunami simulation with the leap-frog scheme (IUGG/IOC Time Project), IOC Manual, UNESCO, No 35

Hatori T (1995) Distribution of tsunami energy along the Japan Sea coast, Zisin J Seismol Soc Jpn 48(2):229-233. https://doi.org/10.4294/zisin1948.48.2_ 229 (written in Japanese with English abstract)

Hatori T, Aida I, Sakashita S, Hibiya T (1983) Field survey of the Nankaido tsunamis inundating Yuasa and Hiro, Wakayama Prefecture: The 1946 Nankaido, 1707 Hoei, and 1854 Ansei tsunamis. Bull Earthq Res Inst Univ Tokyo 58(1):187-206 (written in Japanese with English abstract)

Kawakami G, Kase Y, Urabe A, Takashimizu Y, Nishina K (2017) Tsunamis and possible tsunamigenic deposits along the eastern margin of the Japan Sea. J Geol Soc Jpn 123(10):857-877. https://doi.org/10.5575/geosoc. 2017.0054 (written in Japanese with English abstract)

Kojima Y, Shimozono T, Sato S (2017) Tsunami hazard assessment considering source uncertainties at harbor cities along the northern Japan-Sea coast. J Jpn Soc Civ Eng Ser B2 (coast Eng) 73(2):I_1489-I_1494. https://doi.org/ 10.2208/kaigan.73.I_1489 (written in Japanese with English abstract)

Microbase Co (2010) Micromesh data 2010. https://www.microgeo.biz/. Accessed 10 Aug 2021

Ministry of Land, Infrastructure, Transport and Tourism (2014) Investigation for large earthquakes occurring in the Japan Sea. Ministry of Land, Infrastructure, Transport and Tourism. http://www.mlit.go.jp/river/shinngikai_blog/ daikibojishinchousa/. Accessed 19 Nov 2021 (written in Japanese)

Mulia IE, Ishibe T, Satake K, Gusman AR, Murotani S (2020) Regional probabilistic tsunami hazard assessment associated with active faults along the eastern margin of the Sea of Japan. Earth Planets Space 72:123. https:// doi.org/10.1186/s40623-020-01256-5

Niigata Prefecture (2017) http://npdas.pref.niigata.lg.jp/bosaikikaku/5a092 f7bdf461.pdf. Accessed 22 Nov 2021 (written in Japanese)

Odamaki M (1989) Co-oscillating and independent tides of the Japan Sea. J Oceanogr Soc Jpn 45:217-232. https://doi.org/10.1007/BF02123465

Okada Y (1985) Surface deformation due to shear and tensile faults in a halfspace. Bull Seismol Soc Am 75(4):1135-1154

Project on Earthquakes and Tsunamis in the Japan Sea (2021) https://www. eri.u-tokyo.ac.jp/project/Japan_Sea/houkokusyo.html. Accessed 23 Nov 2021

Rikitake T, Aida I (1988) Tsunami hazard probability in Japan. Bull Seismol Soc Am 78(3):1268-1278. https://doi.org/10.1785/BSSA0780031268

Satake K, Fujii Y, Harada T, Namegaya Y (2013) Time and space distribution of coseismic slip of the 2011 Tohoku earthquake as inferred from tsunami waveform data. Bull Seismol Soc Am 103(2B):14773-21492. https://doi. org/10.1785/0120120122

Sato S, Ando T, Yamanaka Y (2020) Tsunami risk assessment of Niigata City accounting for soil liquefaction and snow melt. Coast Eng Proc 36v:28. https://doi.org/10.9753/icce.v36v.currents.28 
Shuto N (1985) The Nihonkai-Chubu earthquake tsunami on the north Akita Coast. Coast Eng J 28:255-264

Suzuki T, Nishioka Y, Murashima Y, Takayama J, Tanioka Y, Yamashita T (2018) Select tsunami by considering the cumulative probability of occurrence in coasts of the Japan Sea of Hokkaido. J Jpn Soc Civ Eng Ser B2 (coast Eng) 74(2):I_439-I_444. https://doi.org/10.2208/kaigan.74.I_439 (written in Japanese with English abstract)

Tanaka H, Kayane K, Adityawan MB, Roh M, Farid M (2014) Study on the relation of river morphology and tsunami propagation in rivers. Ocean Dyn 64:1319-1332. https://doi.org/10.1007/s10236-014-0749-y

Tanioka Y, Satake K (1996) Tsunami generation by horizontal displacement of the ocean bottom. Geophys Res Lett 23(8):861-864. https://doi.org/10. 1029/96GL00736

Tanioka Y, Satake K (2001) Detailed coseismic slip distribution of the 1944 Tonankai earthquake estimated from tsunami waveforms. Geophys Res Lett 28(6):1075-1078. https://doi.org/10.1029/2000GL012284

Thatcher W (1984) The earthquake deformation cycle at the Nankai Trough, southwest Japan. J Geophys Res Solid Earth 89(B5):3087-3101. https:// doi.org/10.1029/JB089iB05p03087

Weatherall P, Marks KM, Jakobsson M, Schmitt T, Tani S, Arndt JE, Rovere M, Chayes D, Ferrini V, Wigley R (2015) A new digital bathymetric model of the world's oceans. Earth Space Sci 2:331-345. https://doi.org/10.1002/ 2015EA000107

Wessel P, Smith WF, Scharroo R, Luis JF, Wobbe F (2013) Generic mapping tools: improved version released. EOS Trans Am Geophys Union 94(409):410

Woessner J, Farahani RJ (2020) Tsunami inundation hazard across Japan. Int J Disaster Risk Reduct 49:101654. https://doi.org/10.1016/j.ijdrr.2020 101654

Wu Y, Satake K (2018) Synthesis and source characteristics of tsunamis in the Sea of Japan based on normal-mode method. J Geophys Res Solid Earth 123(7):5760-5773. https://doi.org/10.1029/2018JB015707

Yamagata Prefecture (2016) https://www.pref.yamagata.jp/documents/1693/ tunamikaisetu.pdf. Accessed 22 Nov 2021 (written in Japanese)

Yamanaka Y, Shimozono T (2021) Rapid assessment of tsunami source impacts on low-lying coastal areas using offshore wave superposition and static sweep of onshore terrain. Coast Eng J. https://doi.org/10.1080/21664250. 2021.2005364

Yamanaka Y, Sato S, Shimozono T, Tajima Y (2019) A numerical study on nearshore behavior of Japan Sea tsunamis using Green's functions for Gaussian sources based on the linear Boussinesq theory. Coast Eng J 61(2):187-198. https://doi.org/10.1080/21664250.2019.1579462

\section{Publisher's Note}

Springer Nature remains neutral with regard to jurisdictional claims in published maps and institutional affiliations.

\section{Submit your manuscript to a SpringerOpen ${ }^{\odot}$ journal and benefit from:}

- Convenient online submission

- Rigorous peer review

- Open access: articles freely available online

- High visibility within the field

- Retaining the copyright to your article 